\title{
Nonlinear Young's Modulus of New Red Sandstone: Experimental Studies
}

\author{
Evgenii Riabokon ${ }^{1,2} \quad$ Vladimir Poplygin ${ }^{2} \quad$ Mikhail Turbakov $^{2}$ \\ Evgenii Kozhevnikov $^{1,2} \quad$ Dmitrii Kobiakov $^{2} \quad$ Mikhail Guzev $^{2,3} \quad$ Marian Wiercigroch $^{1,2 \star(1)}$ \\ $\left({ }^{1}\right.$ Centre for Applied Dynamics Research, School of Engineering, University of Aberdeen, Aberdeen, UK) \\ $\left({ }^{2}\right.$ Department of Oil and Gas Technologies, Perm National Research Polytechnic University, Perm, Russia) \\ ( ${ }^{3}$ Institute of Applied Mathematics, Far Eastern Branch of the Russian Academy of Sciences, Vladivostok, \\ Russia)
}

Received 26 May 2021; revision received 12 November 2021; Accepted 15 November 2021; published online 11 December 2021

(C) Crown 2021

\begin{abstract}
Young's modulus of New Red Sandstone was investigated experimentally to gain insight into its nonlinear nature. A large experimental programme was carried out by applying a controllable quasi-static and dynamic uniaxial loading to 286 dry sandstone samples of four different sizes. The static and dynamic tests, similar to those aiming at determining the uniaxial compressive strength, were conducted using the state-of-the-art experimental facilities at the University of Aberdeen including a custom-built small experimental rig for inducing a dynamic uniaxial compressive load via a piezoelectric transducer. The obtained results have confirmed a complex nature of Young's modulus of sandstone. Specifically, under a harmonic dynamic loading, it shows strongly nonlinear behaviour, which is hardening and softening with respect to frequency and amplitude of the dynamic loading, respectively.
\end{abstract}

KEY WORDS Sandstone, Young's modulus, Static and dynamic loading, Experiments, Stress and strain, Nonlinearity

A Amplitude of the dynamic load (N)

E Young's modulus $(\mathrm{Pa})$

$E_{\text {dyn }} \quad$ Dynamic component of Young's modulus $(\mathrm{Pa})$

$F \quad$ Load $(\mathrm{N})$

$F_{\text {ex }} \quad$ External load $(\mathrm{N})$

$F_{\max } \quad$ Maximum force $(\mathrm{N})$

$F_{\text {min }} \quad$ Minimum force $(\mathrm{N})$

$F_{\text {max av }} \quad$ Upper load limit of the linear elastic zone $(\mathrm{N})$

$F_{\text {min av }} \quad$ Lower load limit of the linear elastic zone (N)

$F_{\text {rig max }} \quad$ Load limit of the rig $(\mathrm{N})$

$F_{\text {dyn }} \quad$ Dynamic load (N)

$F_{\text {st }} \quad$ Static preload $(\mathrm{N})$

$d \quad$ Diameter of a sample $(\mathrm{m})$

* Corresponding author. E-mail: m.wiercigroch@abdn.ac.uk 
$l \quad$ Length of a sample $(\mathrm{m})$

$l_{\max } \quad$ Maximum length of a sample $(\mathrm{m})$

$l_{\min } \quad$ Minimum length of a sample $(\mathrm{m})$

$\Delta l \quad$ Contraction of a sample $(\mathrm{m})$

$r_{\max } \quad$ Maximum radius of a sample $(\mathrm{m})$

$r_{\min } \quad$ Minimum radius of a sample $(\mathrm{m})$

$\Delta r \quad$ Radial displacement $(\mathrm{m})$

$\varepsilon_{r} \quad$ Linear radial strain (-)

$\varepsilon_{l} \quad$ Linear axial strain $(-)$

$\nu \quad$ Poisson's ratio $(-)$

$\eta_{\text {av }} \quad$ Average Poisson's ratio (-)

$\sigma_{\text {max av }} \quad$ Upper strength limit of a linear elastic zone $(\mathrm{Pa})$

$\sigma_{\text {min av }} \quad$ Lower strength limit of a linear elastic zone $(\mathrm{Pa})$

$\sigma_{\mathrm{UCS}}$ av $\quad$ Average uniaxial compressive strength $(\mathrm{Pa})$

$\sigma_{\text {UCS }} \quad$ Uniaxial compressive strength $(\mathrm{Pa})$

$f \quad$ Frequency $(\mathrm{Hz})$

$b, c, d, h, k$ Rock constants $\left(-,-, \mathrm{N}, \mathrm{GPa} / \mathrm{Hz}^{2}, \mathrm{GPa}\right)$

\section{Introduction}

Changes of geomechanical characteristics of rocks under static and dynamic loading are of significant fundamental and practical importance. Design engineers must consider the static and dynamic geomechanical characteristics of soils and rocks. This includes evaluation of stability of dam slopes during excavations [1], foundation dynamic responses [2], earthquake reliance [3], dynamic strength of rocks in concrete [4] and rocks around tunnels [5], safety of underground mines [6], rock cutting and blasting [7, 8], buildings on limestone sands [9], as well as estimation of reservoir permeability [10].

One of the most important characteristics of mechanical properties of natural and man-made materials used in science and engineering is Young's modulus, which is not only non-constant for rocks but also has a nonlinear character (see e.g. [11]). Studies of the nature of rock's Young's modulus variation under the dynamic loading are insufficient, mostly due to the complexity of custom-made experimental set-ups and subsequent data interpretation (see [7, 12]). Nevertheless, some earlier work (see e.g. [13]) reported that Young's moduli of Navajo sandstone, Spergen limestone and Oklahoma granite are independent of the frequency of dynamic loading at the strain below $10^{-7}$ in the frequency range from 4 to $400 \mathrm{~Hz}$. Recent studies on Opalinus Clay (see [14]) and Mancos shale (see [15]) demonstrated an increase in Young's modulus and a decrease in Poisson's ratio with an increase in frequency of the dynamic loading from 1 to $100 \mathrm{~Hz}$ at the strain around $10^{-6}$. The authors [16] showed that with an increase in frequency from 1 to $50 \mathrm{~Hz}$ for samples with a strain range between $10^{-8}$ and $10^{-6}$, both Young's modulus and Poisson's ratio of Donnybrook sandstone increase, i.e. a dispersion of Young's modulus was observed. A similar dispersion of Young's modulus was also reported in $[17,18]$ for Fontainebleau sandstone for frequencies ranging from 1 to $100 \mathrm{~Hz}$ at the strain lower than $10^{-5}$. An increase in Young's modulus was also shown in [19] whilst studying the Brea sandstone in the range of frequencies from 1 to $100 \mathrm{~Hz}$. A good example of a nonlinear relation for a sedimentary rock's elastic modulus and load frequency was given in [20]. As reported in [21], both sandy and shale formations of Opalinus Clay exhibited relatively strong Young's modulus dispersion at frequencies ranging from 1 to $200 \mathrm{~Hz}$ at the strain lower than $10^{-6}$. Several mechanisms of the nonlinear nature of Young's modulus were proposed, as reviewed in [22], but much more experimental research is still required. The results presented in this study are of a major project focusing on investigating the mechanical properties of rocks, the preliminary results of which have been presented in [23].

The paper is organized as follows. In Sect. 2, details of the experimental methodology, procedures for preparing the samples and inducing static and dynamic uniaxial loads, and set-ups are given. Section 3 focuses on the data processing and discussion of the obtained new results for New Red Sandstone in order to unveil the nonlinear nature of Young's modulus. This is followed by closing remarks presented in Sect. 4. 
Table 1. Diameters and lengths of the cylindrical samples of New Red Sandstone

\begin{tabular}{ll}
\hline Sample size, $\mathrm{mm}$ & \\
$d$, diameter & $L$, Length \\
\hline 24.7 & 51.0 \\
11.5 & 23.0 \\
9.2 & 19.1 \\
7.5 & 15.6 \\
\hline
\end{tabular}

\section{Experimental Methodology}

In this section, we will describe the process of preparing rock samples, the used experimental rigs for static and dynamic tests, as well as the adopted experimental methodology, and present the experimental results. In addition, some details of our unique custom-built experimental set-up for dynamic tests of cylindrical rock samples will also be given.

The main purpose of this paper is to experimentally study the behaviour of the dynamic Young's modulus of dry sandstone samples under uniaxial compression predominantly in the zone of linear elasticity. According to $[24,25]$, the limits of rock's linear elastic zone can be defined on a diagram of uniaxial compression with the relationship between stress and relative longitudinal strain, at which Young's modulus can be calculated. Therefore, to define the limits of the rock's linear elastic zone for New Red Sandstone, a series of tests to determine the uniaxial compressive strength was performed during quasi-static loading of cylindrical samples with four different sizes as listed in Table 1. Based on the results obtained, a sample with a diameter of $d=7.5 \mathrm{~mm}$ and length of $l=15.6 \mathrm{~mm}$ was selected for experiments with non-stationary dynamic loading, for which 270 tests were carried out.

\subsection{Preparation of Samples}

All experiments were carried out on New Red Sandstone of the Permian period sourced from the Clashach Quarry in Scotland, UK. In order to determine the rock's elastic zone and undertake the subsequent dynamic tests, the cylindrical rock samples of four sizes were prepared following the standards given in [26] and ASTM [27], the details of which can be found in Table 1. A total of 286 New Red Sandstone samples in total were milled from large rock blocks by applying similar cutting conditions and flushing out cuttings with water. After milling, the end faces of samples were polished to make them parallel to each other and perpendicular to the samples' geometrical axes. This is to ensure the maximum contact area between the plates of loading rigs and a sample, as well as an even stress distribution. Then samples were washed and kept in a drying oven for $24 \mathrm{~h}$ at the temperature of $90^{\circ} \mathrm{C}$ until their masses became constant, as prescribed by API [28]. The prepared samples were tested for reservoir properties using the UltraPoroPerm-500 apparatus, which utilizes the precision flow measurement technology and differential pressure transducer array to attain the steady-state gas flow for pore volume measurement. Inside the apparatus, a sample is exposed to the static pressure with the pressure difference applied to its opposite ends. The procedure recommended by API [28] was followed to determine the transition from the laminar to the turbulent flow within a sample. The measured porosity and permeability for the New Red Sandstone samples were $17.5 \%$ and $0.353 \mu \mathrm{m}^{2}$, respectively. Due to the high permeability of the investigated New Red Sandstone, the Klinkenberg effect has not been observed.

\subsection{Determination of the Linear Elastic Zone}

The linear elastic zone was determined using the uniaxial compressive strength (UCS) method. The quasi-static tests for the samples with a diameter of $24.7 \mathrm{~mm}$ were conducted on the Instron Series 4483 , and those with a diameter of $7.5 \mathrm{~mm}, 9.2 \mathrm{~mm}$, or $11.5 \mathrm{~mm}$ were carried out on the Tinius Hounsfield apparatus. The loading rate for experiments on both machines was set as $0.05 \mathrm{~mm} / \mathrm{min}$. All tests were carried out in the same environmental conditions; and in order to be statistically viable, for each sample size, 9 loading experiments were performed (Fig. 1).

The quasi-static uniaxial compressive strength test result of the rock sample of $7.5 \mathrm{~mm}$ in diameter is presented in Fig. 2, where a curve of load-displacement together with the snapshots depicting the evolution of cracks is shown. At the beginning of loading, the nonlinear relationship between the load $F$ 


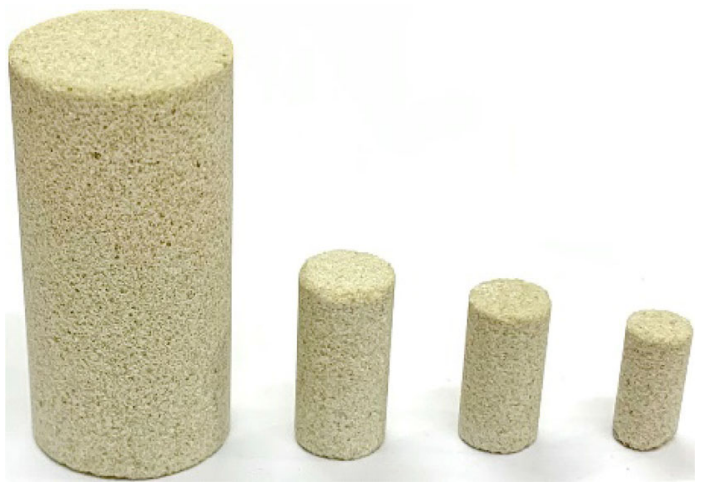

Fig. 1. Photograph of New Red Sandstone cylindrical rock samples used in the experimental studies, which sizes are listed in Table 1

(a)

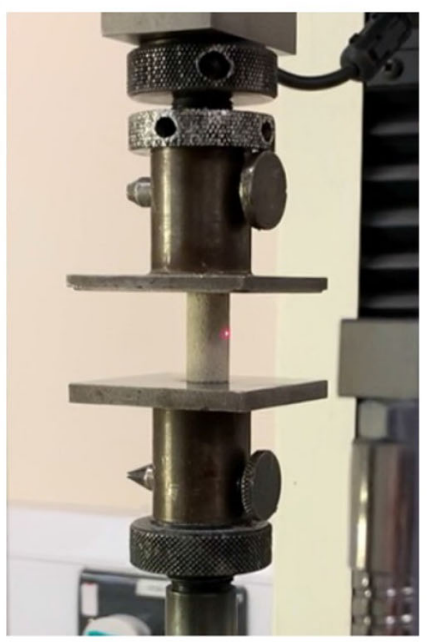

(b)

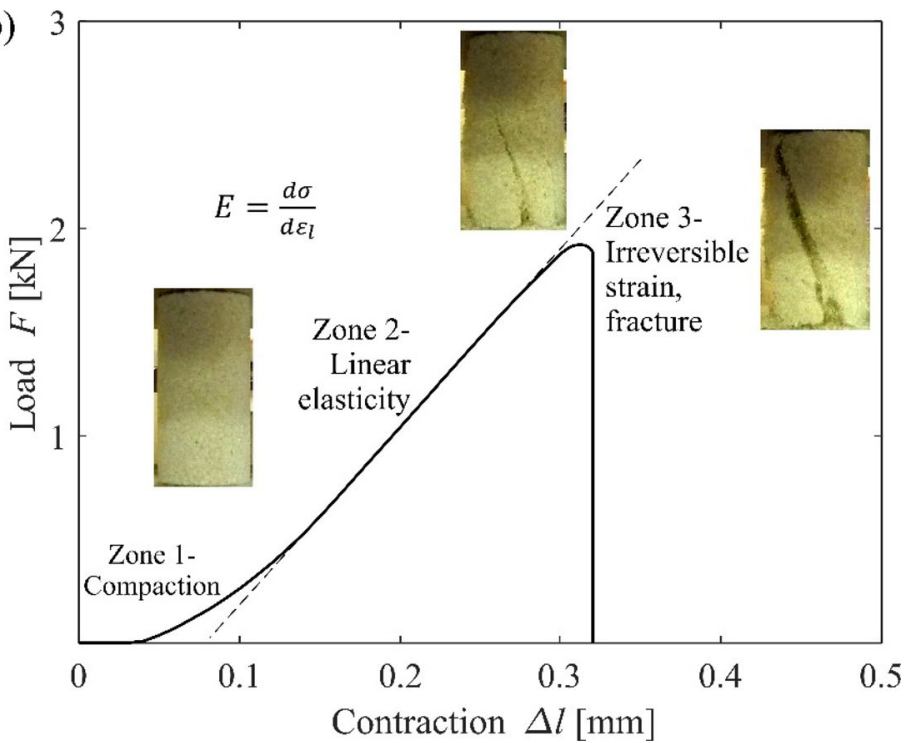

Fig. 2. Quasi-static experiments to determine the linear elastic zone for the New Red Sandstone: a photograph of the Tinius Hounsfield apparatus with a rock sample; b example of load-contraction relationship obtained from uniaxial compressive tests showing two nonlinear (Zones 1 and 3) and one linear (Zone 2) zones. A local value of Young's modulus under the assumption of engineering strain can be calculated as the first derivative of force with respect to contraction divided by the specific axial load. This value is constant for quasi-static load in the linear elastic zone and is represented by a tangent dash line

and the displacement $\Delta l$ is due to two effects: removal of clearance in the force-generating mechanism of the apparatus (the horizontal part of Zone 1) and closure of small cracks and cavities in a rock sample (the nonlinear part of Zone 1). Then, with an increase in load, the zone of linear elasticity (Zone 2) is encountered, where the sample experiences elastic strain. A further increase in load surpassing the elastic limit leads to the determination of uniaxial compressive strength, which is also known as the unconfined compressive strength (UCS) of a material because the confining stress is set to zero. Once the UCS is surpassed, a large crack has developed, leading to a subsequent fracture of the sample, accompanied (as reported in [29]) by a brittle stress drop and a strain softening (Zone 3).

The uniaxial compressive strength $\sigma_{U C S}$ is calculated based on the maximum value of quasi-static axial load causing fracture and the cross section of the sample (e.g. [25]), which, for a cylindrical sample, can be expressed by a simple formula as,

$$
\sigma_{\mathrm{UCS}}=4 \frac{F_{\max }}{\pi d^{2}}
$$



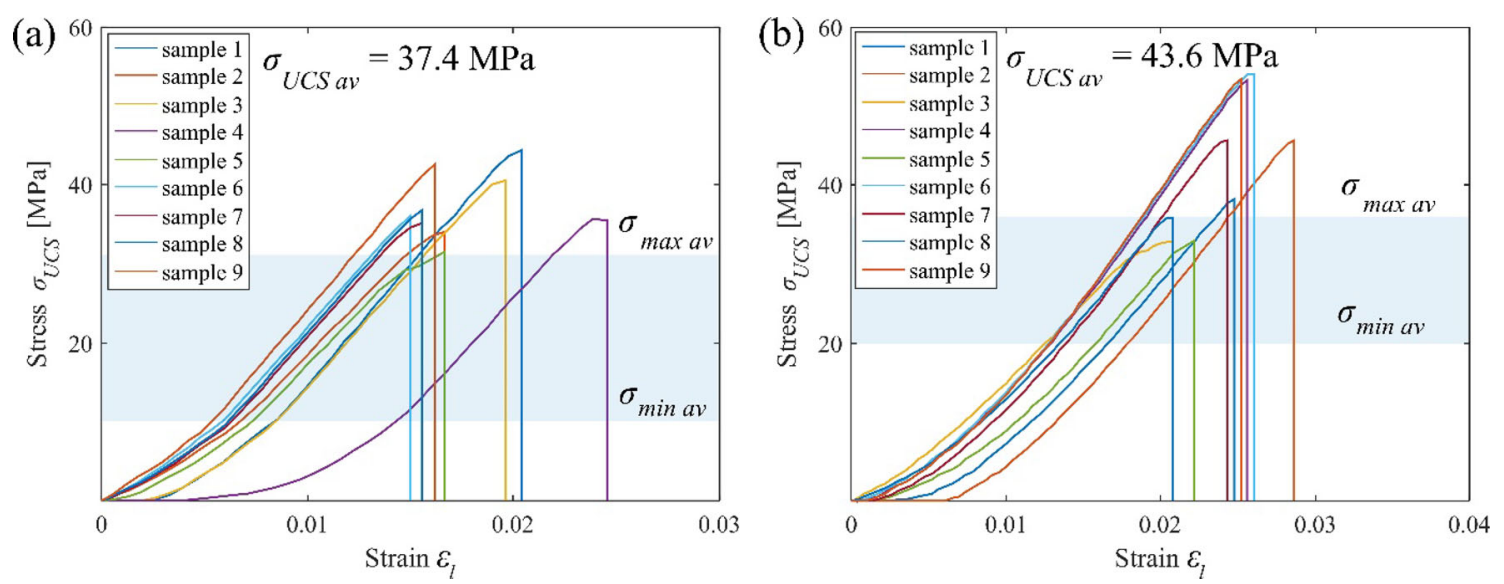

Fig. 3. Stress-strain relationships determined experimentally from the uniaxial quasi-static compression tests for two sizes of samples with diameters of (a) $7.5 \mathrm{~mm}$ and (b) $11.5 \mathrm{~mm}$. To be statistically valid, nine samples were tested for each size, for which the minimum and maximum average values, $\sigma_{\min }$ av and $\sigma_{\max }$ av , of limits of the linear elastic zone were determined. Significant differences can be observed between fracture strengths, but the tangents for the linear elastic zones appear to be similar.

Table 2. Limits of the linear elasticity zone (Zone 2) in terms of minimum and maximum forces and stresses

\begin{tabular}{lllll}
\hline Diameter of sample, $\mathrm{mm}$ & \multicolumn{2}{l}{ Lower limit } & \multicolumn{2}{l}{ Upper limit } \\
\cline { 2 - 5 } & $\sigma_{\min \text { av }}, \mathrm{MPa}$ & $F_{\min \text { av }}, \mathrm{kN}$ & & $F_{\max \text { av }}, \mathrm{MPa}$ \\
\hline 7.5 & 10.2 & 0.45 & 31.7 & 1.5 \\
9.2 & 16.6 & 1.1 & 37.6 & 2.5 \\
11.5 & 24.1 & 2.5 & 41.4 & 4.3 \\
24.7 & 20.9 & 10 & 48.0 & 23.9 \\
\hline
\end{tabular}

where $F_{\max }$ is the maximum force recorded when conducting the UCS tests and $d$ is the diameter of the sample. During these quasi-static tests, we observed a scale effect, which manifested itself in lower $\sigma_{\text {UCS }}$ for smaller samples. Specifically, $30 \%$ lower values of the average uniaxial compressive strength of rock $\sigma_{\mathrm{UCS}}$ av were observed for the smallest samples $(d=7.5 \mathrm{~mm})$ when compared with the largest ones $(d=24.7 \mathrm{~mm})$. This finding contradicts most of the earlier results including those presented in [30,31], where an opposite scale effect was observed. A plausible hypothesis is that during the process of sample preparation, each sample acquires similar size and crack density, which plays a much stronger role for smaller-diameter samples. In fact, a similar explanation of sample surface cracks was given in [32] almost a half century ago. The results reported in [33,34] on uniaxial compression testing of another sedimentary rock, Gosford Sandstone, with sample diameters ranging from 7 to $145 \mathrm{~mm}$, showed that the UCS of the Gosford Sandstone rose with the increase in sample diameter up to $66 \mathrm{~mm}$ and then fell steadily for larger diameters. Another example of rising UCS with sample diameter for sedimentary rock samples was given in [35]. However, it is worth reemphasizing that the above-mentioned results including those presented in this study are not conclusive ones, and a convincing model explaining such behaviour is yet to be developed. There are many aspects including an unavoidable misalignment between the geometric axis of the sample and the applied load, which need to be addressed in future studies to unveil this intriguing behaviour.

A clear demonstration of our finding of lower UCS for smaller-diameter samples is presented in Fig. 3, which compares the uniaxial compressive strength $\sigma_{\mathrm{UCS}}$ obtained from two sets of samples (nine samples per set) of $7.5 \mathrm{~mm}$ and $11.5 \mathrm{~mm}$ in diameter, respectively. The corresponding average uniaxial compressive strength $\sigma_{\mathrm{UCS}}$ av is $37.4 \mathrm{MPa}$ and $43.6 \mathrm{MPa}$, respectively. Each set of stress-strain curves shows a large spread of $\sigma_{\mathrm{UCS}}$, and consequently, the lower and upper limits of the linear elastic zone (Zone 2) are determined, and the three zones are located. This can be seen from Table 2, which provides the lower and upper limits for stresses and forces. 
(a)

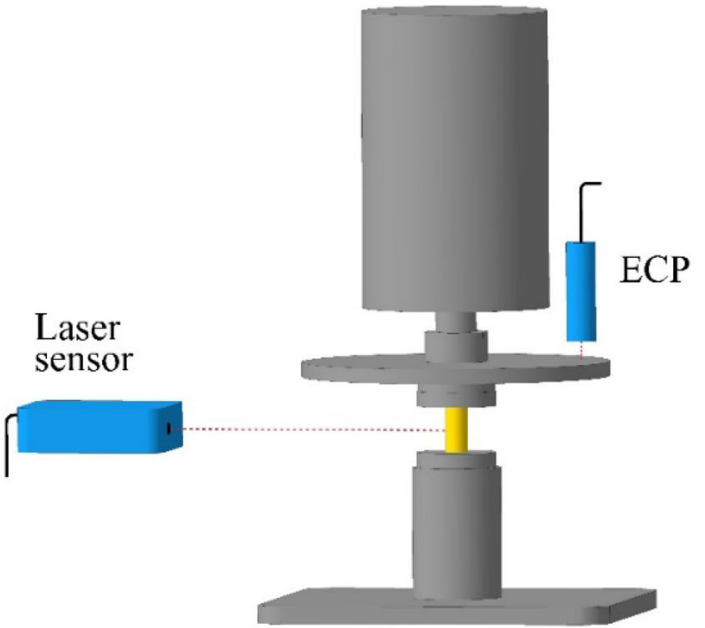

(b)

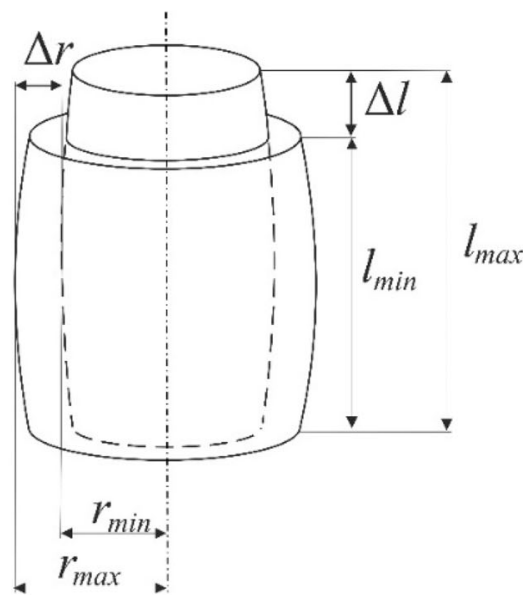

Fig. 4. Dynamic loading generation and measurement of the sample deformation: (a) schematic of the experimental set-up with the axial and radial deformations of a sample, respectively, recorded by an eddy current probe and a laser sensor; (b) schematic of the sample's geometry without deformation and with the maximum deformation. $l_{\min }, l_{\max }$, $r_{\min }$ and $r_{\max }$ are, respectively, the minimum and maximum values of length and radius of a sample under dynamic loading

The stress-strain relationship herein is a complex three-dimensional (3D) problem, where the barreltype deformation of a sample (this is schematically shown in a subsequent part of this paper), the internal microstructure, the distribution of defects, and in particular, the fractality [36] and fissure angle (see [37]) should be considered. However, for the sake of simplicity and to gain some generic insight, we assume the engineering or linear strain in the sample, $\varepsilon_{l}$, which can be calculated as

$$
\varepsilon_{l}=\frac{\Delta l}{l}
$$

where $\Delta l$ and $l$ are the contraction and length of the sample, respectively.

\subsection{Dynamic Tests}

In order to study the variation of Young's modulus of New Red Sandstone with dynamic loading, the generated dynamic stress has to be within the linear elastic zone (Zone 2). This practically means that the piezoelectric actuator being used needs to generate the required dynamic load. The maximum dynamic load that can be generated on our small-scale custom-designed experimental rig, as shown in Fig. 4(a), is $F_{\text {rig } \max }=1.1 \mathrm{kN}$. The set-up utilizes the static loading mechanism from one of the experimental rigs developed by the Centre for Applied Dynamics Research at the University of Aberdeen to study the dynamics of drill-strings [38]. Once a sample is aligned to be at the centre of the axial force and positioned between parallel loading discs, it is preloaded with the static force from the discs' gravity and then the dynamic force generated by the piezoelectric actuator is applied. The pattern of the dynamic loading, in particular the frequency and amplitude of this force, is applied and controlled from the signal generator. As shown schematically in Fig. 4(a), the axial dynamic displacement signal $\Delta l$ is sensed by an eddy current probe (ECP), and the radial motion $\Delta r$ via a laser vibrometer with the accuracy of $0.5 \mu \mathrm{m}$ and $1.5 \mu \mathrm{m}$, respectively. Both signals were conditioned and passed to the LabView data acquisition system to be digitized, recorded, stored and then post-processed. The dynamic experiments were carried out for 30 different harmonic loading patterns defined by a combination of frequency $f$ and loading amplitude $A$ as detailed in Table 3 .

For all the 270 dynamic tests, a sample was first statically preloaded to $F_{\mathrm{st}}=700 \mathrm{~N}$, and then a harmonic force $F_{\mathrm{dyn}}$ of amplitude $A$ varied from 0 to $250 \mathrm{~N}$ and frequency $f$ varied from 15 to $40 \mathrm{~Hz}$ was applied. Considering the experimentally determined limits of the linear elastic zone listed in Table 2, in order to study the dynamic Young's modulus $E_{\mathrm{dyn}}$, the samples with a diameter of $7.5 \mathrm{~mm}$ were used whilst maintaining the necessary condition of rig delivering the force to be within the limits, 
Table 3. Harmonic loading combinations applied in the dynamic tests

\begin{tabular}{lllllll}
\hline Amplitude $F_{\text {dyn }}, \mathrm{N}$ & Frequency & $f, \mathrm{~Hz}$ & & & \\
\cline { 2 - 7 } & 15 & 20 & 25 & 30 & 35 & 40 \\
\hline 50 & 1 & 2 & 3 & 4 & 5 & 6 \\
100 & 7 & 8 & 9 & 10 & 11 & 12 \\
150 & 13 & 14 & 15 & 16 & 17 & 18 \\
200 & 19 & 20 & 21 & 22 & 23 & 24 \\
250 & 25 & 26 & 27 & 28 & 29 & 30 \\
\hline
\end{tabular}
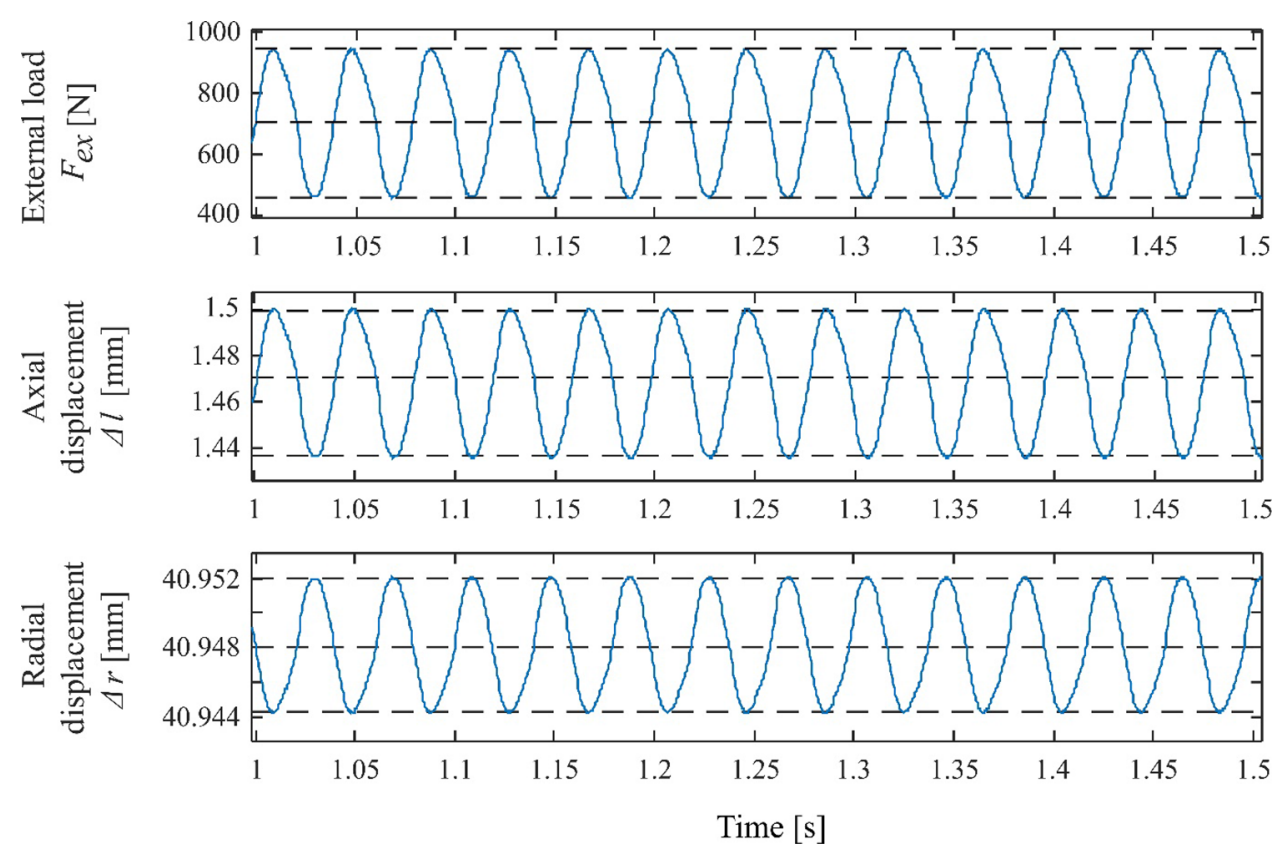

Fig. 5. Time histories of the external loading acting on the sample (top panel) with frequency $f=25 \mathrm{~Hz}$ and amplitude $F_{\text {dyn }}=250 \mathrm{~N}$, and the axial (middle panel) and radial (bottom panel) displacements measured by the eddy current probe and laser vibrometer, respectively

i.e. $F_{\min a v}<F_{\text {rig } \max }<F_{\max a v}$. In other words, such a dynamic uniaxial compressive stress needs to be created, which lies within the zone of linear elasticity (Zone 2), and a more powerful actuator is required for studying the samples with larger diameters of $9.2,11.5$ and $24.7 \mathrm{~mm}$.

To study the dynamic Young's modulus of New Red Sandstone, each sample was initially preloaded with an appropriate value of static force $F_{\text {st }}$ to maintain a good contact between the sample and its holders. Then, the dynamic force of amplitude $F_{\mathrm{dyn}}$ and frequency $f$ was generated. Hence, the selected peak values of the external load, $F_{\min }=F_{\text {st }}-F_{\text {dyn }}$ and $F_{\max }=F_{\text {st }}+F_{\text {dyn }}$, were within the limits of the linear elastic zone (Zone 2), which can be expressed by the inequality (3) as

$$
\left\{\begin{array}{l}
F_{\mathrm{st}}-F_{\mathrm{dyn}}>F_{\min a v} \\
F_{\mathrm{st}}+F_{\mathrm{dyn}}<F_{\max a v}
\end{array}\right.
$$

All the recorded dynamic experimental data were processed using a custom-written Matlab code to accurately locate the local extrema in time histories of dynamic load and displacements. An example family of recorded time histories is shown in Fig. 5, depicting the external loading acting on a sample and the measured amplitudes of the axial $\Delta l$ and radial $\Delta r$ displacements. Using a way similar to the calculation of static engineering strain, as described by Eq. (2), the dynamic strains in the axial $\varepsilon_{l}$ and radial $\varepsilon_{r}$ directions were obtained. In the first instance and at the middle of the sample height, they were used to evaluate the Poisson's ratio $\nu$, with an average value around 0.26. 
(a)

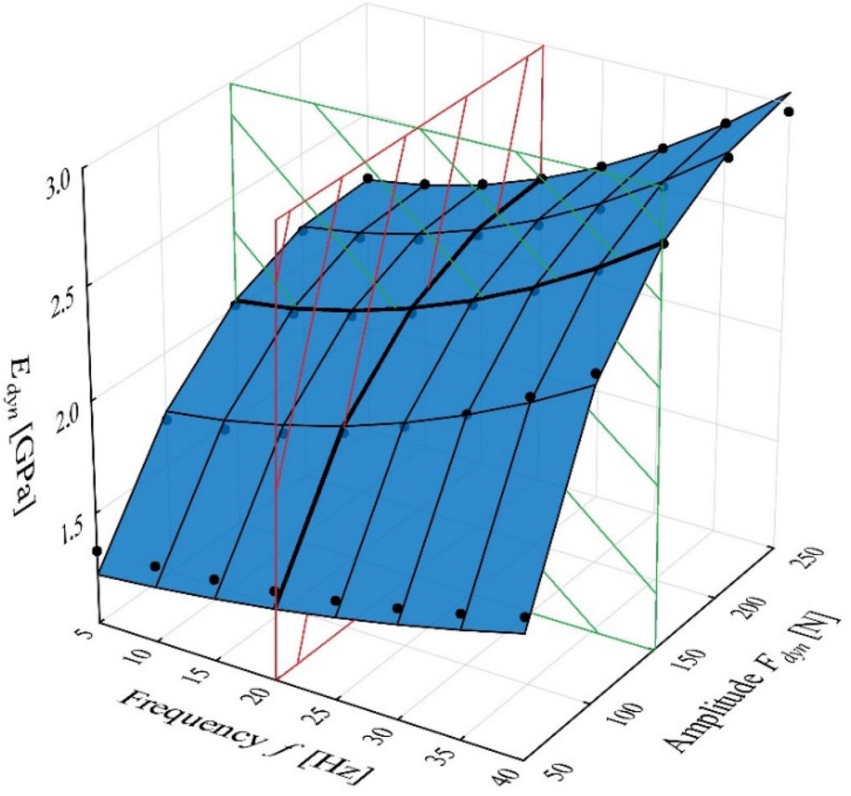

(b)

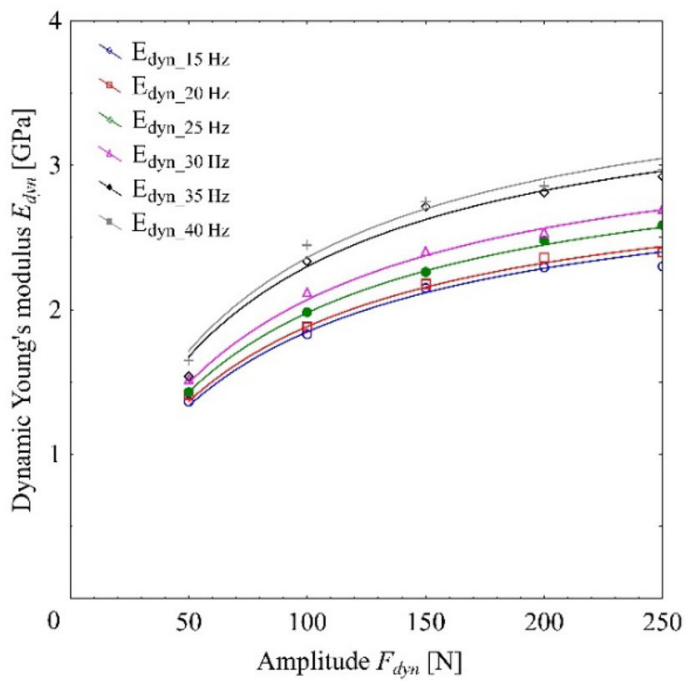

(c)

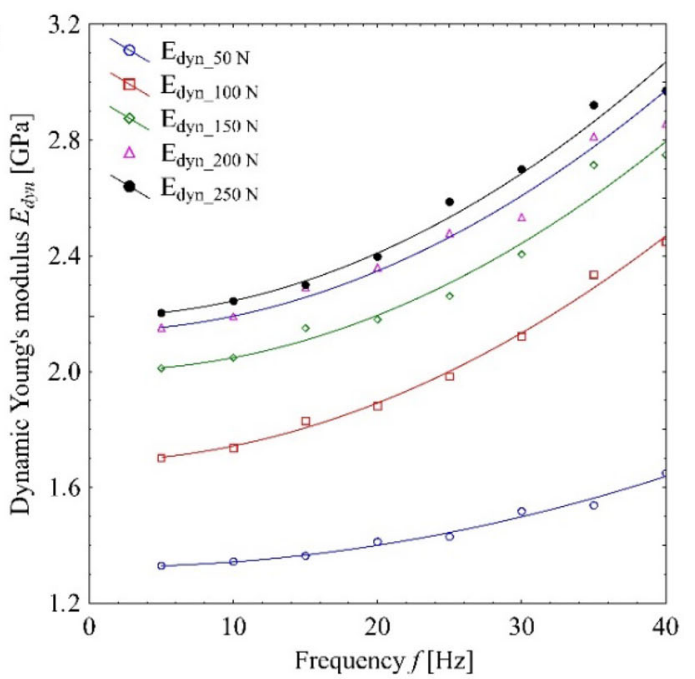

Fig. 6. Nonlinear nature of the dynamic Young's modulus $E_{\mathrm{dyn}}$ of New Red Sandstone determined experimentally: (a) 3D surface of $E_{\text {dyn }}$ determined using the method of least squares intersecting the planes of constant amplitude and frequency; (b) and (c) the softening and hardening characteristics of $E_{\mathrm{dyn}}$ with respect to the amplitude $F_{\mathrm{dyn}}$ and frequency $f$ of dynamic loading, respectively. The legends in panels (b) and (c) denote the corresponding curves with various amplitudes and frequencies

\section{Nature of Young's Modulus of New Red Sandstone}

The experimental data of the dynamic forces and displacements (axial and radial) were used to compute the stress-strain relationships by assuming that a sufficient fundamental insight can be obtained using the engineering (linear) strain definition. Specifically, this approach was used to determine Young's modulus and its dependence on the frequency and amplitude of dynamic loading. The dynamic Young's modulus $E_{\text {dyn }}$ shows strong nonlinear behaviour, as presented in Fig. 6, where panel (a) depicts the 3D surface intersected by two planes of constant amplitude $F_{\mathrm{dyn}}$ and frequency $f$, calculated using the method of least squares with respect to the functions of amplitude and frequency dependence represented by Eqs. (4) and (5). The panels (a) and (b) of Fig. 6 demonstrate the softening and hardening characteristics of the dynamic Young's modulus $E_{\mathrm{dyn}}$ for varying amplitude and 
Table 4. Values of material constants describing $E_{\mathrm{dyn}}$ by a family of curves with Eq. (4)

\begin{tabular}{llll}
\hline Frequency $f[\mathrm{~Hz}]$ & Constants & \\
\cline { 2 - 4 } & $b[-]$ & $c[-]$ & $d[\mathrm{~N}]$ \\
\hline 15 & 0.024 & 0.008 & 0.5 \\
20 & 0.0273 & 0.009 & 0.55 \\
25 & 0.0273 & 0.0085 & 0.53 \\
30 & 0.0273 & 0.0081 & 0.51 \\
35 & 0.037 & 0.0101 & 0.6 \\
40 & 0.042 & 0.0111 & 0.67 \\
\hline
\end{tabular}

Table 5. Values of material constants describing $E_{\mathrm{dyn}}$ by a family of curves with Eq. (5)

\begin{tabular}{llllll}
\hline Constants & \multicolumn{5}{l}{ Amplitude $F_{\text {dyn }}[\mathrm{N}]$} \\
\cline { 2 - 6 } & 50 & 100 & 150 & 200 & 250 \\
\hline$h\left[\mathrm{GPa} / \mathrm{Hz}^{2}\right]$ & 0.00019 & 0.00047 & 0.00049 & 0.00051 & 0.00054 \\
$k[\mathrm{GPa}]$ & 1.325 & 1.69 & 2.0 & 2.14 & 2.19 \\
\hline
\end{tabular}

frequency, respectively. In other words, the tangent curves of dynamic Young's modulus with respect to amplitude and frequency would monotonically decrease and increase, respectively.

In the experiments used to determine Fig. 6 , as specified in Table 3 , the amplitude $F_{\text {dyn }}$ ranged from 50 to $250 \mathrm{~N}$ whilst the frequency $f$ from 15 to $40 \mathrm{~Hz}$. With an increase in load amplitude $F_{\text {dyn }}$ from 0 to $100 \mathrm{~N}$, the Young's modulus rose from 1.8 to $2.4 \mathrm{GPa}$ with the largest gradient. The increase in amplitude $F_{\text {dyn }}$ from 100 to $250 \mathrm{~N}$ led to an additional rise of Young's modulus by around $0.7 \mathrm{GPa}$ tending towards a constant value. The dynamic Young's modulus $E_{\mathrm{dyn}}$ depending on the dynamic load amplitude $F_{\mathrm{dyn}}$ can be graphically represented as a family of curves shown in Fig. $6 \mathrm{~b}$ and approximated mathematically by a rational function of the following type:

$$
E_{\mathrm{dyn}}\left(F_{\mathrm{dyn}}\right)=\frac{b F_{\mathrm{dyn}}}{c F_{\mathrm{dyn}}+d}
$$

where $b, c$ and $d$ are material constants of New Red Sandstone, which are given in Table 4 for different values of $F_{\mathrm{dyn}}$.

We adopted a similar approach when analysing the variation of Young's modulus $E_{\mathrm{dyn}}$ with respect to the frequency $f$ of dynamic loading. However, the relationship herein is best approximated by quadratic functions, which is graphically shown in Fig. 6c and described as

$$
E_{\text {dyn }}(f)=h f^{2}+k
$$

where $h$ and $k$ are constants. Herein, the higher the amplitude of dynamic loading $F_{\text {dyn }}$ is, the higher $h$ becomes. There is the smallest rise of $E_{\text {dyn }}$ by $0.3 \mathrm{GPa}$ when the frequency of dynamic loading $f$ is increased from 0 to $40 \mathrm{~Hz}$ at the amplitude $F_{\text {dyn }}$ equal to $50 \mathrm{~N}$. When $F_{\text {dyn }}$ is increased to $250 \mathrm{~N}$, the Young's modulus rises more rapidly and its increment reaches the maximum $E_{\mathrm{dyn}}=0.8 \mathrm{GPa}$. The values of $h$ and $k$ describing the evolution of Eq. (5) are given in Table 5.

\section{Closing Remarks}

In this paper, we present the results from a large experimental programme which was conducted to investigate the nonlinear dynamic nature of Young's modulus of New Red Sandstone. Specifically, 286 dry sandstone samples of a cylindrical shape and four different sizes were tested by inducing a controllable dynamic loading in a similar way to the uniaxial compressive strength tests.

The experiments were carried out in two stages. In the first stage, tests were conducted by inducing quasi-static loading to determine the linear zone of Young's modulus. Samples with a diameter of $7.5 \mathrm{~mm}, 9.2 \mathrm{~mm}$, or $11.5 \mathrm{~mm}$ were tested with the Tinius Hounsfield apparatus, whilst those with a diameter of $24.7 \mathrm{~mm}$ were tested on the Instron Series 4483 . The loading rate was set to $0.05 \mathrm{~mm} / \mathrm{min}$ on both machines. Three distinct zones were observed for all experiments, namely two nonlinear zones 
at the initial and final phases (Zones 1 and 3), and one linear zone (Zone 2) in between, as seen in Fig. 2b.

The obtained results have confirmed a strongly nonlinear nature of the Young's modulus of New Red Sandstone, which shows hardening and softening characteristics with respect to the frequency and amplitude of harmonic loading, respectively. It is clearly seen that the change of amplitude $F_{\text {dyn }}$ of the dynamic loading at any investigated frequency $f$ has a much more dominant effect on the increase in the dynamic Young's modulus $E_{\text {dyn }}$ than the change of frequency of the dynamic loading has, as shown in Fig. 6.

Although the dispersion of Young's modulus has been mentioned in literature [14, 16, 17], it has not been supported by robust experimental data or mathematical models. Therefore, our studies may facilitate the development of modelling the dynamic characteristics of clastic rocks.

Acknowledgements. The authors would like to acknowledge the generous financial support from the Russian Science Foundation (Project No. 19-19-00408).

Open Access This article is licensed under a Creative Commons Attribution 4.0 International License, which permits use, sharing, adaptation, distribution and reproduction in any medium or format, as long as you give appropriate credit to the original author(s) and the source, provide a link to the Creative Commons licence, and indicate if changes were made. The images or other third party material in this article are included in the article's Creative Commons licence, unless indicated otherwise in a credit line to the material. If material is not included in the article's Creative Commons licence and your intended use is not permitted by statutory regulation or exceeds the permitted use, you will need to obtain permission directly from the copyright holder. To view a copy of this licence, visit http://creativecommons.org/ licenses/by/4.0/.

\section{References}

[1] Wang S, Wang $\mathrm{H}, \mathrm{Xu} \mathrm{W}$, et al. Investigation on mechanical behaviour of dacite under loading and unloading conditions. Géotech Lett. 2019;9(2):1-6.

[2] Darshyamkar R, Kumar A, Manna B. Investigation of block foundations resting on soil-rock and rock-rock media under coupled vibrations. J Rock Mech Geotech Eng. 2017;9(2):305-17.

[3] Okada T, Naya T. A new model for evaluating the dynamic shear strength of rocks based on laboratory test data for earthquake-resistant design. J Rock Mech Geotech Eng. 2019;11(5):979-89.

[4] Petrov YV, Smirnov IV, Volkov GA, et al. Dynamic failure of dry and fully saturated limestone samples based on incubation time concept. J Rock Mech Geotech Eng. 2017;9(1):125-34.

[5] Qian Q, Qi C, Wang M. Dynamic strength of rocks and physical nature of rock strength. J Rock Mech Geotech Eng. 2009;1(1):1-10.

[6] Geranmayeh Vaneghi R, Ferdosi B, Okoth AD, et al. Strength degradation of sandstone and granodiorite under uniaxial cyclic loading. J Rock Mech Geotech Eng. 2018;10(1):114-26.

[7] Xia K, Yao W, Wu B. Dynamic rock tensile strengths of Laurentian granite: experimental observation and micromechanical model. J Rock Mech Geotech Eng. 2017;9(1):116-24.

[8] Jiang Y-Z, He K-F, Dong Y-L, et al. Influence of load weight on dynamic response of vibrating screen. Shock Vib. 2019;2019:4232730.

[9] Lv Y, Liu J, Xiong Z. One-dimensional dynamic compressive behavior of dry calcareous sand at high strain rates. J Rock Mech Geotech Eng. 2019;11(1):192-201.

[10] Xu P, Yang S-Q. Influence of stress and high-temperature treatment on the permeability evolution behavior of sandstone. Acta Mech Sin/Lixue Xuebao. 2019;35:419-32.

[11] He M, Li N. Experimental research on the non-linear energy characteristics of granite and sandstone. Géotech Lett. 2020;10(3):385-92.

[12] Subramaniyan S, Quintal B, Tisato N, et al. An overview of laboratory apparatuses to measure seismic attenuation in reservoir rocks: apparatuses to measure seismic attenuation. Geophys Prospect. 2014;62(6):1211-23.

[13] Spencer JW Jr. Stress relaxations at low frequencies in fluid-saturated rocks: attenuation and modulus dispersion. J Geophys Res. 1981;86(B3):1803-12.

[14] Lozovyi S, Bauer A. From static to dynamic stiffness of shales: frequency and stress dependence. Rock Mech Rock Eng. 2019;52:5085-98.

[15] Szewczyk D, Bauer A, Holt RM. A new laboratory apparatus for the measurement of seismic dispersion under deviatoric stress conditions. Geophys Prospect. 2016;64(4):789-98.

[16] Mikhaltsevitch V, Lebedev M, Gurevich BA. A laboratory study of the elastic and anelastic properties of the sandstone flooded with supercritical $\mathrm{CO}_{2}$ at seismic frequencies. Energy Procedia. 2014;63:4289-96. 
[17] Pimienta L, Fortin J, Guéguen Y. Bulk modulus dispersion and attenuation in sandstones. Geophysics. 2015;80(2):A25-30.

[18] Pimienta L, Fortin J, Guéguen Y. Effect of fluids and frequencies on Poisson's ratio of sandstone samples. Geophysics. 2016;81(2):D183-95.

[19] Tisato N, Quintal B. Measurements of seismic attenuation and transient fluid pressure in partially saturated Berea sandstone: evidence of fluid flow on the mesoscopic scale. Geophys J Int. 2013;195(1):342-51.

[20] Batzle ML, Han D-H, Hofmann R. Fluid mobility and frequency-dependent seismic velocity - direct measurements. Geophysics. 2006;71(1):N1-9.

[21] Lozovyi S, Bauer A. Static and dynamic stiffness measurements with Opalinus Clay. Geophys Prospect. 2018;67(4):997-1019.

[22] Müller TM, Gurevich B, Lebedev M. Seismic wave attenuation and dispersion resulting from wave-induced flow in porous rocks: a review. Geophysics. 2010;75(5):X75A147-75A164.

[23] Guzev M, Kozhevnikov E, Turbakov M, et al. Experimental studies of the influence of dynamic loading on the elastic properties of sandstone. Energies. 2020;13(23):6195.

[24] ISRM Suggested methods for determining the uniaxial compressive strength and deformability of rock materials. Int J Rock Mech Min Sci Geomech Abstr 16(2) 135-140 (1979)

[25] Jaeger JC, Cook NGW, Zimmerman RW. Fundamentals of rock mechanics. 4th ed. Malden, USA: Blackwell Publishing; 2007.

[26] ISRM Suggested methods for determining tensile strength of rock materials. Int J Rock Mech Min Sci Geomech Abstr 15(3) 99-103 (1978)

[27] ASTM D4543: Standard practices for preparing rock core specimens and determining dimensional and shape tolerances. West Conshohocken, PA, USA: American Society for Testing and Materials International (2001)

[28] Recommended Practices for Core Analysis. Recommended Practice 40. 2nd ed. Washington, USA: American petroleum institute; (1998).

[29] Yang S-Q, Hu B, Xu P. Study on the damage-softening constitutive model of rock and experimental verification. Acta Mech Sin/Lixue Xuebao. 2019;35:786-98.

[30] Zaitsev DV, Kochanov AN, Toktogulov Sh.Zh, et al. The influence of the scale effect and heterogeneity of rocks in determining their strength properties. Mount Inf Analyt Bul. 2016;11:208-11.

[31] Hoek E, Brown ET. Underground excavations in rock. London: The Institution of Mining and Metallurgy, Stephen Austin and Sons Ltd., Hertford, London, p. 527 (1980)

[32] Vutukuri VS, Lama RD, Saluja SS. Handbook on mechanical properties of rocks. Bay Village, Ohio: Trans Tech Publications; 1974.

[33] Masoumi H, Douglas KJ, Russell A.. Experimental Investigation of the Size Effect of Gosford Sandstone. In: Proceedings of the 11th Australia New Zealand conference on geomechanics ANZ 2012, Melbourne, Australia, 15-18 (July 2012). pp. 644-649

[34] Wang S, Oh J, Masoumi H, et al.: Scale-size and structural effects of rock materials Scale-Size and Structural Effects of Rock Materials, 1-648 (2020)

[35] Hawkins AB. Aspects of rock strength. Bull Eng Geol Environ. 1998;57:17-30.

[36] Bazant ZP. Scaling of quasibrittle fracture: hypotheses of invasive and lacunar fractality, their critique and Weibull connection. Int J Fract. 1997;83:41-65.

[37] Yang S-Q, Huang Y-H, Ranjith PG, et al. Discrete element modeling on the crack evolution behavior of brittle sandstone containing three fissures under uniaxial compression. Acta Mech Sin/Lixue Xuebao. $2015 ; 31(6): 871-89$.

[38] Kapitaniak M, Vaziri Hamaneh V, Chávez JP, et al. Unveiling complexity of drill-string vibrations: experiments and modelling. Int J Mech Sci. 2015;101-102:324-37. 